\section{Crustal Permeability}

\section{by Tom Gleeson and Steve Ingebritsen (Eds.)}

November, 2016 by AGU/ Wiley-Blackwell, $472 \mathrm{p}$., ISBN 978-1-119-16656-6

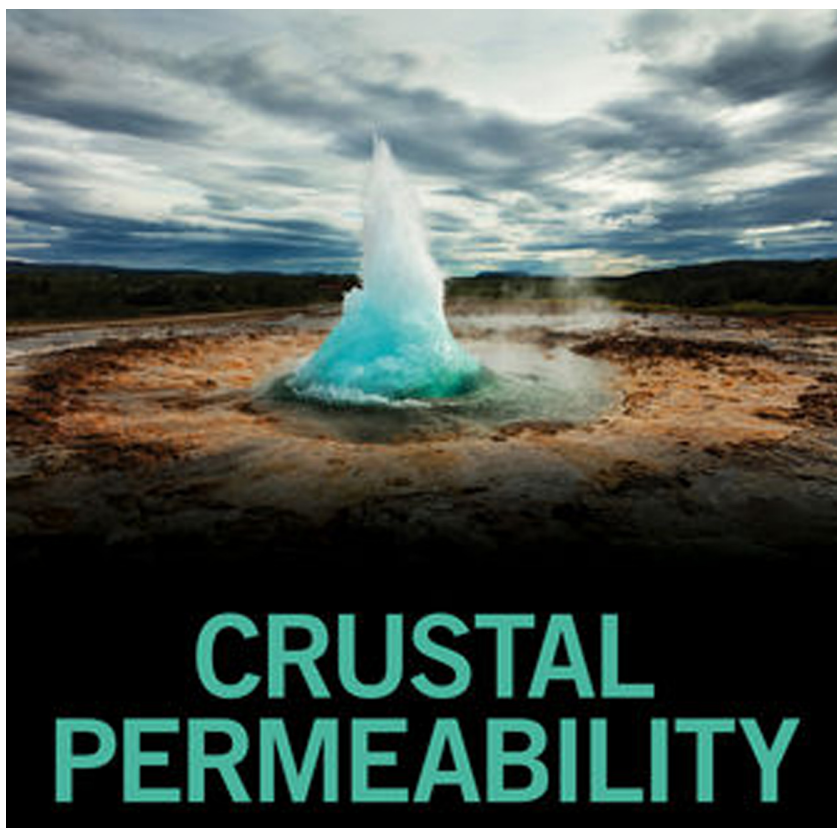

Tom Gleeson and Steve Ingebritsen Editors

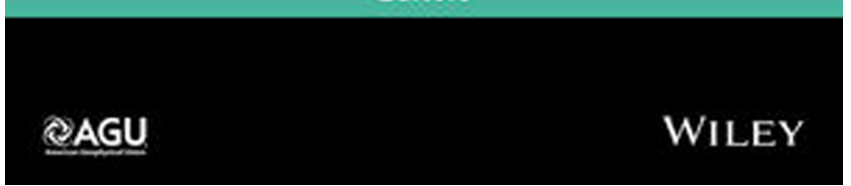

Although there are thousands of research papers on crustal permeability, this is the first book-length treatment of the subject. The topic of crustal permeability is of broad interest in light of the controlling effect of permeability on diverse geologic processes and also timely in light of the practical challenges associated with emerging technologies such as hydraulic fracturing for oil and gas production ('fracking'), enhanced geothermal systems, and geologic carbon sequestration.

This book is also motivated by the historical dichotomy between the hydrogeologic concept of permeability as a static material property that exerts control on fluid flow and the perspective of economic geologists, geophysicists, and crustal petrologists who have long recognized permeability as a dynamic parameter that changes in response to tectonism, fluid production, and geochemical reactions.

In their introduction of the book (Chapter 1), the editors clearly state the motivation and background of the book. Issues associated with fracking, enhanced geothermal systems, and geologic carbon sequestration have already begun to promote a constructive dialog between the static and dynamic views of permeability, and the editors of this book made a conscious effort to include both viewpoints. They assembled a team of worldwide experts in the field who authored the 30 chapters of the book covering both direct measurement of permeability in the uppermost crust and inferential permeability estimates, mainly for the deeper crust.

Chapter 2 entitled "DigitalCrust - a 4D data system of material properties for transforming research on crustal fluid flow" is dedicated to the "DigitalCrust" - a community-governed, four-dimensional data system of the Earth's crustal structure and the Crustal Permeability data portal associated with this book. This portal gives access to numerous rich tools and resources available for this text.

The remainder book chapters focus on separate areas of research and application. Rigorous and yet accessible, the book chapters are grouped in four parts, based on the topics they cover: The physics of permeability, Static permeability (Sediments and sedimentary rocks, Igneous and metamorphic rocks), Dynamic permeability (Oceanic crust, Fault zones, Crustal-scale behavior, Effects of fluid injection at the scale of a reservoir or ore-deposit) and Conclusions. Additional summary and synthesis sections are provided before and after the three main sections of the book: The physics of permeability, Static permeability and Dynamic permeability. Though each chapter could be a stand-alone reading, it is apparent that the authors made an effort to coordinate with the editors the content of different chapters.

Concluding with an exhaustive bibliography of significant references and a very well organized index, the book addresses the broad interdisciplinary aspects of crustal permeability.

The book is clearly written and the text, figures, and tables are produced to a high quality. Powerpoints of all figures from the book are available for downloading from the student companion site for Crustal Permeability.

Crustal Permeability certainly deserves to find its way on to the bookshelves of geologists, geophysicists, and crustal petrologists. The book represents a significant contribution to the challenging field of crustal permeability and should be recommended as a reference for university libraries serving crustal engineering related programs, as well as for research corporations, and engineering consulting firms.

\section{Mihail E. Popescu}

Illinois Institute of Technology, Chicago, US

E-mail: mihail.e.popescu@gmail.com 